\section{Interresponse time as a factor in choice*}

\author{
DOUGLAS J. NAVARICK $†$ and EDMUND FANTINO \\ University of California, San Diego, La Jolla, Calif. 92037
}

Pigeons' pecks in the presence of two concurrently available initial-link stimuli produced one of two (mutually exclusive) terminal-link stimuli on equal variable-interval schedules. Pecks during terminal-link stimuli produced food on fixed-interval schedules. In three of four birds, the probability of a peck increased on one key as a function of the time since the last choice response on either key. In the fourth bird, the probability of a peck increased with interresponse time on whichever key was pecked last (perseveration). Thus, choice responses terminating different interresponse times may not be functionally equivalent, or quantitatively interchangeable, in concurrent schedules.

Shimp (1966) has shown that pigeons' choices of an alternative often vary as a function of the location of previous responses (left or right). The present study examined choice as a function of the time since the last choice response (interresponse time or IRT). In particular, two questions were addressed: (1) Given a peck on the left or right key, what is the probability that the next peck will fall on the same key if X sec have elapsed since the last peck? (2) Does this probability vary systematically as a function of $X$ ? If so, choice responses terminating different IRTs may not be functionally equivalent.

Our criterion of functional equivalence is analogous to the one employed by Skinner (1935). Skinner noted that rates of leverpressing often remained constant despite variations in the topography of responses. Because these variations left rates unchanged, the component topographies were regarded as "quantitatively mutually replaceable." In our application, if the probability of successive pecks on the same key were comparable for pecks terminating "long" and "short" IRTs, then pecks terminating different IRTs would be functionally equivalent in Skinner's sense. Variations in the number of IRTs which were long or short would not alter the overall probability of successive pecks. On the other hand, if the probability of successive pecks differed for long and short IRTs, then pecks terminating different IRTs would not be functionally equivalent.

\section{SUBJECTS}

Four male White Carneaux pigeons were maintained at approximately $80 \%$ of ad lib weight. All birds had previously responded on

* Research supported by NSF Grant GB-13418 and NIMH Grant MH-20752 to the University of Califormia, San Diego.

HNational Institute of Mental Health predoctoral fellow. concurrent-chains schedules such as those described below. APPARATUS

The experimental chamber (Ferster \& Skinner, 1957) contained a solenoid-operated grain hopper centrally located between two response keys, mounted 3 in. apart and $9 \mathrm{in}$. above the floor. Stimulus projectors (One Plane Digital Display Unit, IEE, Model 10495) were used to transilluminate the keys with white, blue or green light. During reinforcement, which lasted 2 or $6 \mathrm{sec}$, two 6-W houselights were turned off and the feeding aperture was illuminated. A minimum force of $12.15 \mathrm{~g}$ was required to operate the keys. Each peck on a lighted key produced auditory feedback by operating a $110-\mathrm{V}$ ac relay. White noise masked extraneous sounds. Standard electromechanical programming equipment was located in an adjacent room.

\section{PROCEDURE}

\section{Concurrent Chains}

Choice behavior was studied with a concurrent-chains schedule of reinforcement (Autor, 1960; Fantino, 1969). The pigeons responded on two keys illuminated by the color (white) associated with the initial links of two chained schedules (Ferster \& Skinner. 1957). A peck during the initial links occasionally achieved entry into one of two terminal links. Each terminal link became available for entry on a variable-interval (VI) 56-sec schedule. When one terminal link became available, the VI timer associated with that link stopped operating while the alternate timer continued to operate. Upon production of a terminal-link. stimulus (blue on the left, green on the right), both VI timers stopped and the alternate key became dark and inoperative. Further responding on the lighted side produced food on a fixed-interval (FI) 5 -sec schedule. Following reinforcement, the initial links were reinstated. If both terminal links had been made available at the time one terminal link was entered, the terminal link that was not entered remained available after reinforcement. Sessions terminated after 40 reinforcements. A diagram of the concurrentchains procedure is presented in Fig. 1.

Choice proportions for terminal-link conditions were calculated by dividing the number of initial-link responses on one key by the sum of the initial-link responses on both keys. Reported values are based on performances during a 9-day stability period. After 18 days and every day thereafter until stability was reached, the choice proportions of the last 9 days were divided into three successive blocks of three sessions. Performance was considered stable when the means of these blocks satisfied two conditions: (1) the difference between any two means did not exceed $.05 ;(2)$ there were no upward or downward trends, i.e., neither $\bar{X}_{1}<\bar{X}_{2}<\bar{X}_{3}$ nor $\bar{X}_{1}>$ $\overline{\mathrm{X}}_{2}>\overline{\mathrm{X}}_{3}$. Choice proportions are the means of the daily performances over these 9 days.

In the first experimental condition, the duration of reinforcement was $2 \mathrm{sec}$ on each key. Choice proportions which deviated from .50 would presumably reflect position or color preferences and might be correlated with a characteristic temporal pattern of responding. In the second condition, the duration of reinforcement was $6 \mathrm{sec}$ on whichever key yielded the lower choice proportion in the previous phase and $2 \mathrm{sec}$ on the alternate key. Would the temporal pattern of the first condition

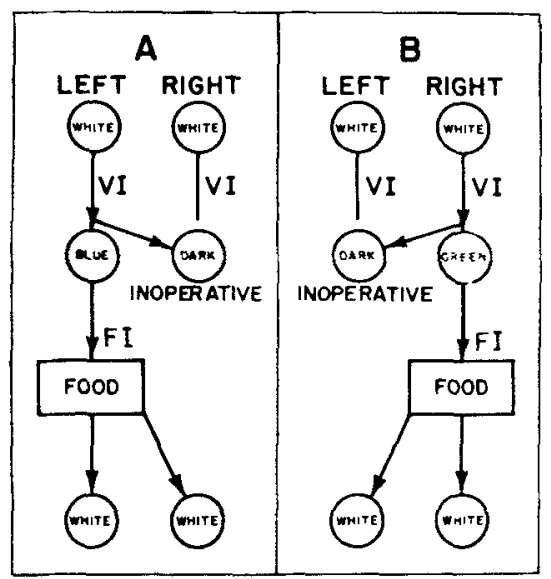

Fig. 1. Diagram of the concurrent-chains procedure. The left side of the diagram (A) illustrates the sequence of events when behavior was reinforced on the left key; the right side (B) illustrates the sequence of events when behavior was reinforced on the right. See text for details. 


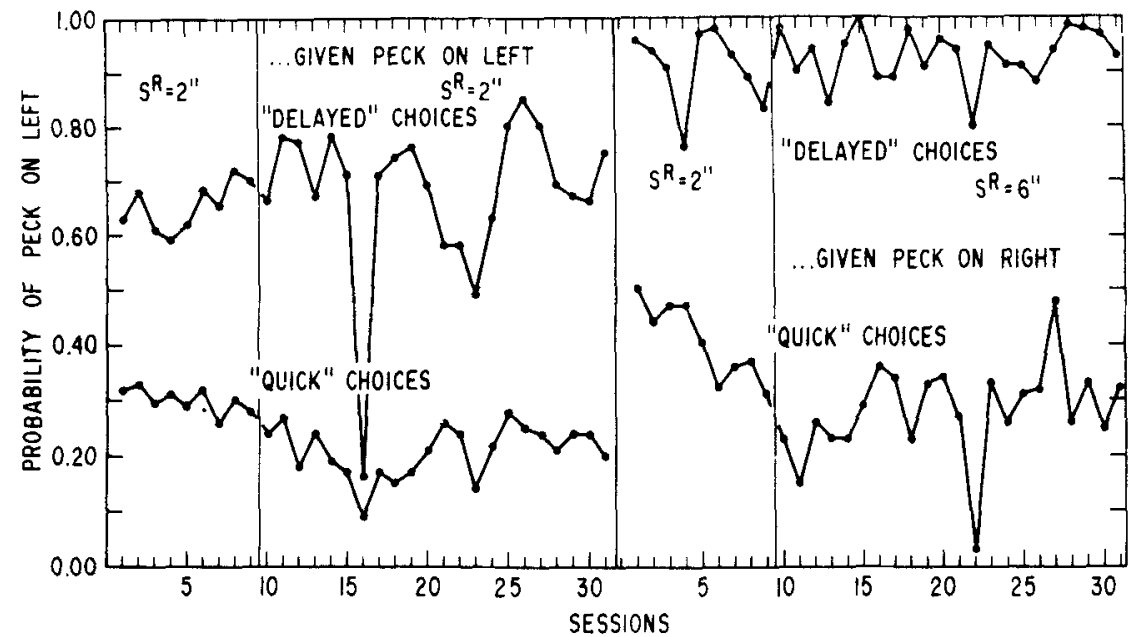

Fig. 2. Probability of a peck on the left key for responses emitted "quickly" (IRT <.5 sec) and for responses emitted after a "delay" (IRT > .5 sec, Bird 3). The left half of the figure shows the probability of a peck on the left when the previous peck was also on the left; the right half shows the probability of a peck on the left when the previous peck was on the right. In each half of the figure, the portion of the functions to the left of the vertical line represents the stability period of Condition 1 (equal reinforcement durations). The remaining portion of the functions represents the prestability and stability period for Condition 2 (unequal reinforcement durations, as indicated). The graph shows that the probability of a peck on the left key increased with IRT, irrespective of the location of the previous peck. This was true of both reinforcement conditions.

remain the same, or would it shift in some systematic way?

"Quick" Vs "Delayed" Choices

The probability of successive pecks on a key (Reynolds, 1963) is a measure of the relative frequency of two response sequences: repetitions and changeovers. For example, if the left key were pecked (L), the next peck could fall either on the left key (LL) or the right key (LR). The probability of a repetition on the left, or at least two successive pecks, would be $L L /(L L+L R)$. The repetition rates on the left and right keys are logically independent and do not necessarily sum to unity, as do choice proportions. For example, whereas the sum of the probabilities of LL and LR must equal unity, the sum of the probabilities of $L L$ and $R R$ need not. Two rates were obtained for each key, one for all sequences emitted with IRTs less than .5 sec ("quick" choices) and another for all sequences emitted with IRTs greater than $.5 \mathrm{sec}$ ("delayed" choices). This criterion yielded a substantial number of sequences in most cases. Samples of less than 50 sequences were omitted from the analysis.

\section{RESULTS AND DISCUSSION}

All birds showed correlations between choice and IRT. The most frequent pattern of responding was an increase in the probability of a peck on one of the two keys as time passed since the last choice response. This pattern is illustrated in Fig. 2, which shows the probability of a peck on the left $k$ ey across sessions for Bird 3 . The left half of the graph gives the probability of a peck on the left, given that the last peck was also on the left; the right half gives the probability of a peck on the left, given that the last peck was on the right. In each half of the graph, the portion of the functions to the left of the vertical line represents the stability period for Condition 1. The remainder of the functions represents the prestability and stability periods for Condition 2 . Bird 3 showed an increase in the probability of a peck on the left when a "delay" intervened before the response in both reward conditions. This increase occurred whether the previous peck was on the left or on the right. If the bird pecked the left key, and delayed, it pecked that key again. If it pecked the right key, and delayed, it changed over to the left. Because a single key exercised control over the response, we shall label this arrangement a "key pattern."

Table 1 presents choice proportions and repetition rates for each bird. Entries are the means of the nine session values during the stability period. The column labeled "reversals" indicates the number of times during the stability period that the difference between quick and delayed choices was opposite in direction to the difference between the average values for quick and delayed choices. For example, if the entries in the table indicated that quick choices gave higher repetition rates than delayed choices and the number of reversals was two, then in two sessions out of nine, delayed choices gave higher repetition rates than quick choices.

Table 1

Probability of Successive Pecks on Left $\left(P_{L L}\right)$ and $R$ ight $\left(P_{R R}\right)$ Keys as a Function of Interresponse Time

\begin{tabular}{|c|c|c|c|c|c|c|c|c|c|c|}
\hline \multirow[b]{2}{*}{ Bird } & \multicolumn{2}{|c|}{$\begin{array}{l}\text { Reinforcement } \\
\text { Duration (Sec) }\end{array}$} & \multirow{2}{*}{$\begin{array}{c}\begin{array}{c}\text { Choice } \\
\text { Proportion } \\
\text { (Left) }\end{array} \\
\end{array}$} & \multicolumn{3}{|c|}{$\mathbf{P}_{\mathrm{LL}}$} & \multicolumn{3}{|c|}{$\mathbf{P}_{\mathrm{RR}}$} & \multirow[b]{2}{*}{ Sessions } \\
\hline & Left & Right & & Quick* & Delay ed** & $\begin{array}{l}\text { Rever- } \\
\text { salst }\end{array}$ & Quick & Delayed & $\begin{array}{l}\text { Rever- } \\
\text { sals }\end{array}$ & \\
\hline 3 & $\begin{array}{l}2 \\
2 \\
2(V) \\
2(V)\end{array}$ & $\begin{array}{r}2 \\
6 \\
6 \\
6,06\end{array}$ & $\begin{array}{l}.57 \\
.51 \\
.22 \\
.23\end{array}$ & $\begin{array}{l}.30 \\
.23 \\
\overline{.22}\end{array}$ & $\begin{array}{l}.65 \\
.70 \\
- \\
-\end{array}$ & $\begin{array}{c}0 \\
0 \\
- \\
-\end{array}$ & $\begin{array}{l}.60 \\
.68 \\
.74 \\
.72\end{array}$ & $\begin{array}{l}.09 \\
.06 \\
.80 \\
.80\end{array}$ & $\begin{array}{l}0 \\
0 \\
3 \\
2\end{array}$ & $\begin{array}{l}20 \\
24 \\
18 \\
19\end{array}$ \\
\hline 5 & $\begin{array}{l}\mathbf{2} \\
\mathbf{2}\end{array}$ & $\begin{array}{l}2 \\
6\end{array}$ & $\begin{array}{l}.59 \\
.55\end{array}$ & $\begin{array}{l}.48 \\
.45\end{array}$ & $\begin{array}{l}.62 \\
.47\end{array}$ & $\begin{array}{l}2 \\
4\end{array}$ & $\begin{array}{l}.42 \\
.44\end{array}$ & $\begin{array}{l}.15 \\
.20\end{array}$ & $\begin{array}{l}0 \\
1++\end{array}$ & $\begin{array}{l}20 \\
20\end{array}$ \\
\hline 11 & $\begin{array}{l}2 \\
6\end{array}$ & $\begin{array}{l}2 \\
2\end{array}$ & $\begin{array}{l}.49 \\
.75\end{array}$ & $\begin{array}{l}.27 \\
.61\end{array}$ & $\begin{array}{l}.35 \\
.73\end{array}$ & $\begin{array}{l}2 \\
1\end{array}$ & $\begin{array}{l}.13 \\
.06\end{array}$ & .46 & $\frac{0}{-}$ & $\begin{array}{l}24 \\
23\end{array}$ \\
\hline 12 & $\begin{array}{l}2 \\
6 \\
\end{array}$ & $\begin{array}{l}2 \\
2 \\
\end{array}$ & $\begin{array}{l}.45 \\
.68\end{array}$ & $\begin{array}{l}.31 \\
.46\end{array}$ & $\begin{array}{l}.12 \\
.70\end{array}$ & $\begin{array}{l}1 \\
1\end{array}$ & $\begin{array}{l}.10 \\
.15\end{array}$ & $\stackrel{.65}{-}$ & $\frac{0}{-}$ & $\begin{array}{l}22 \\
22\end{array}$ \\
\hline
\end{tabular}

*IRTs $<.5 \mathrm{sec} \quad * * I R T \mathrm{~s}>.5 \mathrm{sec}$

+ Number of days during stability period showing difference opposite in direction to that of indicated means.

$+\uparrow B$ ased on 8-day period (equipment failure). 
Hyphens appear in several cells of the table. The total number of sequences in these cells was less than 50, and such sequences were therefore excluded from the analysis.

When reinforcement durations were equal on the left and right keys, three of the four birds (Birds 3,5 , and 12) showed key patterns such as the one in Fig. 2: the probability of successive pecks on one of the keys increased with IRT, while the probability of successive pecks on the other key decreased with IRT (i.e., the probability of changing over from the other key increased). In each case, there was a correspondence between this key pattern and the choice proportion: the key for which a higher choice proportion was shown was also the key on which the probability of a peck increased as a function of IRT. For example, Bird 3 gave a choice proportion for the left key of .57 in Condition 1 and also showed an increase in the probability of pecking this key as time passed since the last choice response (on either key).

When reinforcement duration was increased on the nonpreferred key, two of these birds ( 3 and 5 ) showed little change in their choice proportions and the temporal pattern of Condition 1 remained essentially the same. Because a higher choice proportion would ordinarily be expected on the key which provided the greater reinforcement duration, steps were taken to alter the choice proportions. For Bird 3, the initial links were reduced from VI 56 sec to VI $15 \mathrm{sec}$ on both keys, a manipulation that increases any difference in reinforcing value between two stimuli (Fantino, 1969). After stability was achieved, the initial links were increased to VI 30 sec. A higher choice proportion for the key providing the greater reinforcement duration was shown in each of these conditions. The temporal pattern of the previous conditions was also altered, with the repetition rate for delayed choices now exceeding the repetition rate for quick choices on the right key. (Bird 5 expired before similar procedures could be instituted.)

In Condition 2, Bird 12 showed a higher choice proportion for the 6-sec reinforcement than for the 2 -sec one, and the temporal pattern of Condition 1 (equal reinforcement durations) was reversed. In Condition 1 , the repetition rate for delayed choices exceeded the repetition rate for quick choices on the right key, while the repetition rate for delayed choices was lower than the repetition rate for quick choices on the left (i.e., the probability of a peck on the right increased with IRT). In Condition 2 , the repetition rate for delayed choices exceeded the repetition rate for quick choices on the left, a reversal of the previous relationship.

Bird 11 differed from the other birds in that it showed a "perseverative" pattern of responding in the first condition rather than a key pattern. With reinforcement durations equal on the two keys (Condition 1), the probability of successive pecks increased with IRT on both keys. A key pattern, in contrast, was defined as one in which the probability of successive pecks increased with IRT on one key but decreased on the other. In Condition 2, presentation of the 6-sec reinforcement duration altered the temporal pattern of responding in a fashion similar to that indicated for Birds 3 and 12. As the choice proportion on the left increased, the delayed repetition rate on that key increased relative to the quick repetition rate.

In summary, the present results show that choice often varies as a function of the time since the last choice response. Whenever a shift in reinforcement contingencies was effective in altering choice proportions, the temporal pattern of responding changed as well. Where the shift in contingencies was ineffective in altering choice, the temporal pattern of responding was largely unchanged. Two temporal patterns emerged: a "key pattern," in which a peck on one key became more likely as IRT increased, irrespective of the location of the last peck, and a "perseverative pattern," in which a peck became more likely on the key last pecked as IRT increased. The relationship between quick and delayed choices on a key could be modified by increasing the bird's preference for that key. As the choice proportion on a key increased, the repetition rate for delayed choices increased relative to the repetition rate for quick choices. That is, the longer the organism "waited" after a peck on the preferred key, the more likely it was to respond again on that key. These relationships suggest that choice responses terminating different IRTs may not be functionally equivalent in concurrent schedules. The present data permit a functional distinction between at least two types of response: "quick" choices (relatively short IRTs) and "delayed" choices (relatively long IRTs).

\section{REFERENCES}

AUTOR, S. M. The strength of conditioned reinforcers as a function of frequency and probability of reinforcement. Unpublished doctoral dissertation, Harvard University, 1960.

FANTINO, E. Choice and rate of reinforcement. Journal of the Experimental Analysis of Behavior, 1969 , $12,723-730$.

FERSTER, C. B., \& SKINNER, B. F. Schedules of reinforcement. New York: Appleton-Century-Crofts, 1957.

REYNOLDS, G. S. On some determinants of choice in pigeons. Journal of the Experimental Analysis of Behavior, 1963, 6. 53-59.

SHIMP, C. P. Probabilistically reinforced choice behavior in pigeons. Journal of the Experimental Analysis of Behavior, 1966, $9.443-455$.

SKINNER, B. F. The generic nature of the concepts of stimulus and response. Jourral of General Psychology, 1935, 12 , $40-65$. 